\title{
The widening spectrum of neurological damage in liver disease
}

\author{
ROGER WILliAMS \\ M.D., M.R.C.P. \\ P. J. TOGHILL \\ M.D., M.R.C.P. \\ Physician and Medical Tutor \\ Senior Medical Registrar \\ King's College Hospital and Medical School, London, S.E.5
}

MucH has been learnt about hepatic encephalopathy since the Eck fistula was first performed some 110 years ago. Yet new clinical syndromes continue to be reported and, although recent studies have led to a better definition of the neuropathological changes, the biochemical disorder is still uncertain. Fortunately, this has not deterred new approaches to treatment.

\section{Clinical syndromes}

In acute liver failure the development of impaired consciousness carries a grave prognosis. Whether the aetiology is infective hepatitis, drug toxicity or acute yellow atrophy of pregnancy, the clinical manifestations of the neurological state appear to progress in the same basic pattern. It is difficult to better the description of Lucké \& Mallory (1946). In reviewing the case reports of 196 American servicemen dying from viral hepatitis they described the terminal phase as beginning with listlessness, drowsiness and incoherence. Some patients had restless symptoms of excitement advancing to mania whereas others had alternating apathy and delirium. In the later stages there was coma, increased tendon reflexes, extensor plantar responses with, at times, muscle twitching, opisthotonus and convulsions. In fulminating hepatitis, particularly in young children, the neurological symptoms may precede, by as much as $48 \mathrm{hr}$, the appearance of jaundice.

The various neuro-psychiatric manifestations which may complicate chronic liver disease were clearly described by Summerskill et al. (1956) over 10 years ago and are now well recognized. More recently it has become apparent that some patients with recurrent or chronic symptoms may progress to a more permanent neurological disorder which Victor, Adams \& Cole (1965) have termed acquired hepato-cerebral degeneration.
This occurs with all types of cirrhosis and the fixed neurological syndromes may sometimes appear without preceding episodes of hepatic precoma or coma.

Part of the symptom complex can be related to a chronic and progressive dementia. Initially there is loss of the sophisticated habits of civilized living. Some patients remain superficially alert but may have impairment of recent memory and paucity of spontaneous thought. In other patients reversible fluctuations of mood from apathy to wild excitement may occur whilst in a further group frank psychotic symptoms with hallucinations and paranoid delusions dominate the picture (Read et al., 1967).

Probably the most consistent neurological features of hepato-cerebral degeneration are related to disorders of the cerebellar and extrapyramidal systems. Tremors of the hands varying from a fine resting tremor, as seen in Parkinsonism, to the well-described flapping tremor may be encountered. Other patients may have tremor of the lips and tongue. Bizarre symptoms of choreo-athetosis may occur with facial grimacing, lip-smacking, tongue protrusion and writhing sinuous or tortuous convulsions of the arms and legs (Gibson, 1963; Toghill, Johnston \& Smith, 1967). Rarely there may be myoclonic jerks of the limbs which have been termed 'intention or action myocolonus' (Lance \& Adams, 1963).

Disorders of the pyramidal system are common with brisk reflexes, ankle clonus and extensor plantar responses. Unilateral neurological signs are unusual but Pearce (1963) has observed transient hemiparesis, permanent hemiplegia and focal epilepsy in association with hepatic pre-coma and coma.

A true myelopathy can also occur. This is 
characterized by extreme spasticity, and Liversedge \& Rawson (1966) have recently drawn attention to the late retention of flexor plantar responses. They suggest that the initial change in the myelopathy is an alteration in the $\gamma$-loop threshold with, at a later stage, demyelination of the pyramidal pathways but not to levels above the cervical cord.

Although peripheral neuropathy has been only rarely recorded in liver disease it may be more common than is generally recognized. Dayan \& Williams (1967) found evidence of a demyelinating peripheral neuropathy in each of the ten patients they examined with widely differing types of hepatic disease. Retro-bulbar neuritis may also occur (Ortiz-Vázquez, 1967) and a Guillain-Barré syndrome complicating acute viral hepatitis has been described (Dragsted, 1950).

\section{Differential diagnosis}

Probably the most confusing situation in the diagnosis of patients with liver disease and neurological abnormalities is concerned with cases of Wilson's disease with no family history. The neurological signs of dementia, choreo-athetosis, tremor and myoclonus may be indistinguishable from acquired hepato-cerebral degeneration, though usually Wilson's disease presents at an earlier age with less emphasis on hepatic symptoms. Denny-Brown (1964) considers that the neurological abnormalities in Wilson's disease can be separated into two groups. The first ('pseudosclerosis'), which tends to present in adult life, is characterized by a flapping wrist tremor, a 'wing-beating' effect at the shoulders and dysarthria. The second ('progressive lenticular degeneration') begins earlier in childhood with dystonia and abnormal postures of the limbs, a fixed facial expression, inattentiveness and occasional schizoid symptoms. According to Denny-Brown the adult pseudosclerosis type which carries a better prognosis and is helped by treatment with chelating agents may be the direct effect of copper deposition in the brain, whereas the juvenile dystonic variety which carries a poor prognosis and may be aggravated by chelation is possibly related to the underlying liver disease. Unfortunately the serum caeruloplasmin level is not always low, but Kayser-Fleischer rings are diagnostic of Wilson's disease though they may require slit lamp examination for detection, and radio-copper studies can be helpful (Osborn \& Walshe, 1967).

Further difficulties may occur in the diagnosis of hepatic neurological disease in subjects with chronic alcoholism but not necessarily cirrhosis. These patients may develop various neuro- psychiatric syndromes such as delirium tremens, Wernicke's encephalopathy, and Korsakoff's psychosis, whereas some may also show signs of a peripheral neuropathy or an alcoholic cerebellar degeneration (Victor, Adams \& Mancall, 1959). When the patient has cirrhosis and hepatocerebral changes in addition, a complex neurological state results.

\section{Neuropathological changes}

The detailed studies of Victor et al. (1965) have shown that there are two abnormalities; firstly, a diffuse increase in the size and number of the protoplasmic astrocytes and, secondly, a patchy vacuolar degeneration and necrosis of the nerve cells which usually occurs in bands in the deeper layers of the cerebral cortex and, to a lesser extent, in the basal ganglia and in the cerebellum.

There is some, but not complete, correlation between the type of neurological disorder experienced in life and the site of lesions at autopsy. The slowly progressive dementia is probably dependent on the widespread cortical lesions. The hippocampal and diencephalic systems which appear to be critical for memory and learning are affected less than other regions, and this would explain why these functions are not disproportionately affected as in Korsakofl's psychosis (Victor et al., 1965). The cerebellare symptoms also correlate with lesions in the cere-? bellar cortex but there is a poor correlation between choreoathetosis and lesions of the basal ganglia.

The changes in the astrocytes are perhaps the most fascinating and puzzling feature of this disorder. These may be the only finding in patients dying in acute hepatic coma though presumably there is some functional impairment of the neuronal parenchymal cells with changes too slight to be visible on light microscopy. In patients dying after a protracted but single episode of hepatic coma widespread parenchymal changes can occur, and in the various chronic syndromes there is a fairly close correlation between the topography of the parenchymal and astrocytic lesions (Victor et al., 1965). The exact function of the protoplasmic astrocytes is unknown but they may be concerned with the transport of essential substances from capillary to neurone, in which case it could be postulated that the nerve cell injury is secondary to a pathological process acting primarily on the astrocytes. Whatever the exact relationship it is important to remember that chronic clinical syndromes with dysarthria or ataxia do not necessarily have irreversible morphological changes in the nerve cells 
and some cases are reported in which considerable improvement occurred after colonic exclusion (McDermott, Victor \& Point, 1962).

\section{Neuropathological distinction from Wilson's disease}

In general, changes in the basal ganglia are usually more pronounced in Wilson's disease. Intranuclear glycogenic inclusions in the astrocytes are less common and Opalski cells (a form of lipid-laden degenerating nerve cell) are more frequent. However, there are many cases which are indistinguishable from acquired hepatocerebral degeneration and this raises many problems in relation to the exact role of copper toxicity in the pathogenesis of the disorder. The close pathological similarity of the two diseases is not, as might be suggested, a reflection of a limited range of response of cerebral tissue to injury. The protoplasmic astrocytic changes are seen only in these two disorders and the overall neuropathological picture, as Victor and his colleagues stress, is quite different from that resulting from other types of toxic or metabolic cerebral injury such as following anoxia or hypoglycaemia.

\section{Biochemical disorder}

The increased incidence of encephalopathy in cirrhosis after portacaval anastomosis (Grace, Muench \& Chalmers, 1966) and the development of a typical chronic hepatocerebral degeneration after a shunt operation in two patients who had a normal liver (Adams, 1965) shows the importance of the collateral circulation as opposed to hepatocellular impairment in the pathogenesis of this disorder. The complete diversion of portal blood as in a shunt operation may, however, impair liver function even in a previously normal liver. The liver decreases in size after a portacaval shunt and in one of Adams' cases severe hypoproteinaemia developed. Furthermore studies by Thompson, Williams \& Sherlock (1964) in the closely comparable situation of extrahepatic portal hypertension due to a portal-vein thrombosis showed definite and progressive impairment of liver function.

Much evidence points to ammonia as a toxic substance responsible for hepatic coma (reviewed by Summerskill, 1966). The blood ammonia level is usually raised in acute hepatic coma, the disorder can be precipitated by the feeding of ammonium salts, and neomycin, which reduces bacterial breakdown of protein in the large bowel, is undoubtedly effective in controlling both clinical symptoms and in reducing blood ammonia level. Furthermore, patients with certain inborn errors of metabolism involving the urea cycle, of which argininosuccinic aciduria is one example, may have a raised blood ammonia and neurological disorders including episodes of confusion and coma, which resemble hepatic encephalopathy (Moser et al., 1967). On the other hand, numerous workers have been worried by the lack of exact correlation between neurological signs and ammonia levels, and there can be no doubt that substances such as methionine when given orally, and sedative drugs like morphine, can precipitate hepatic coma in cirrhosis without any change in ammonia metabolism (Read, 1965).

It has been suggested that ammonia acts by producing a depletion of the Krebs' cycle intermediate $\alpha$-ketoglutarate as a result of excess conversion to glutamic acid and glutamine. High glutamine levels have been demonstrated both in the brain and in the cerebrospinal fluid in hepatic coma, but liberation of ketoglutarate from the brain rather than uptake occurs (Dastur, Seshadri \& Talageri, 1963).

Recently, Schenker et al. (1967) have produced direct evidence that toxic doses of ammonia can in vivo actually affect cerebral energy metabolism. They showed a substantial decrease in adenosine triphosphate and phosphocreatine concentration in the base of the brain but not in the cortex of ammonia-intoxicated rats. Whatever the initial basic injury the final picture is a complicated one and includes respiratory alkalosis and electrolyte disturbances, particularly hypokalaemia, together with various changes in carbohydrate, short-chain fatty acid and aminoacid metabolism (reviewed by Read, 1965 ; Zieve, 1966).

\section{Advances in treatment}

Standard therapy at present consists of dietary protein restriction, emptying of the bowel by purgation and neomycin therapy, together with attention to electrolyte imbalance and correction of precipitating factors such as over-diuresis, infection or haemorrhage. Remarkable improvement can occur both in acute coma and in some of the various chronic syndromes. Nevertheless, the mortality of coma due to infective hepatitis or massive necrosis from drug toxicity remains about $80 \%$ and in these conditions some form of temporary liver support is needed. The recent developments of exchange transfusion and extracorporeal hepatic perfusion afford some hope.

Improvement with exchange transfusion may result from the addition of deficient factors to the circulation, possibly antibody (Morris, Gocke \& Sardi, 1967), or from the removal of toxic substances. Saunders (1967) in Cape Town, whose group were largely responsible for intro- 
ducing the technique, continues to get good results. Eleven of the twenty-two patients treated to date recovered consciousness completely and six patients are alive and well. They found that fresh frozen plasma was of help in controlling the haemorrhagic tendency and that intravenous albumin was needed to correct hypoalbuminaemia. Some patients developed hypoglycaemia and the blood sugar should be estimated routinely. Most of the patients were children with infective hepatitis and the experience reported from this country, mainly in adults, is less encouraging. Three of the seven patients treated by Jones et al. (1967) showed striking improvement in the level of consciousness but all seven died. Necropsy in six showed such distortion of hepatic architecture as to suggest that macronodular cirrhosis would have been inevitable. Indeed, two of Saunders' successful cases now have cirrhosis and it may well be that at a certain stage of lobular disorganization restitution of normal structure is impossible. However, exchange transfusion is a relatively simple procedure and in our view is worth-while when the patient fails to respond to standard measures within $24 \mathrm{hr}$.

Perfusion of the patient's blood through a cooled isolated pig or cadaver human liver in an extracorporeal circuit, unlike exchange transfusion, requires extensive facilities and a large team. Such isolated perfused livers can function satisfactorily for periods of up to $8 \mathrm{hr}$. Oxygen is utilized, bile is produced and bilirubin and ammonia are removed from the patient's blood. Approximately a third of the patients treated have shown neurological improvement although relatively few have recovered completely (Eiseman, 1966 ; Watts et al., 1967).

\section{Chronic encephalopathy}

A number of attempts have been made to reduce ammonia production in the large bowel by altering the bacterial flora. Lactobacillus acidophilus has been given in milk (Macbeth, Kass \& McDermott, 1965) or as the freeze-dried preparation Enpac (Read et al., 1966). The lactobacilli are thought to impede coliform multiplication as a result of lowering faecal $\mathrm{pH}$ but clinical improvement has not necessarily correlated with coliform stool counts. Fenton, Knight \& Humpherson (1966) produced some improvement in three patients by feeding a diet containing milk and cheese protein instead of the normal mixed animal protein. The beneficial action may be due to the high bacterial content of the diet altering the bacterial flora.

Alternatively faecal pH may be changed by giving lactulose (1-4-beta-galactosidofructose).
This is a synthetic disaccharide which cannot be hydrolysed by the small intestinal enzymes in man and is split in the large bowel into organic acids. Some diarrhoea results due to fer- $c$. mentation of carbohydrates and an improvement $\overrightarrow{\vec{F}}$ in encephalopathy comparable with neomycin was obtained in two patients (Bircher et al., 1966).

A more complete and possibly more permanent response can be obtained by surgical exclusion of the colon with an ileo-sigmoidostomy. Cirrhotic patients in general withstand surgical of operations badly and this operation should be $\vec{\circ}$ restricted to patients with good liver function. In some of the patients reported there has been a striking improvement in mental status and ability to tolerate protein. Symptoms such as dysarthria, ataxia and extra-pyramidal symptoms may or may not improve (MacDermott et al., 1962 ; Walker et al., 1965). Blood ammonia falls though it may rise later as a result of colonization of the small bowel by urea-splitting organisms.

\section{References}

ADAMs, R.D. (1965) In: Progress in Liver Disease (Ed. by H. Popper and F. Schaffner), Vol. II, p. 442. Grune \& Stratton, New York.

Bircher, J., Muller, J., Guggenheim, P. \& Haemmerli U.P. (1966) Treatment of chronic portal-systemic en cephalopathy with lactulose. Lancet, $\mathbf{i}, 890$.

Dastur, D.K., Seshadri, R. \& TAlageri, V.R. (1963 Liver-brain relationships in hepatic coma. Arch. intern. Med. 112, 899.

Dayan, A.D. \& Williams, R. (1967) Demyelinating peripheral neuropathy and liver disease. Lancet, ii, 133.

DenNY-Brown, D. (1964) Hepatolenticular degeneration (Wilson's disease). New Engl. J. Med. 270, 1149.

DRAGSTED, P.J. (1950) Guillain-Barré-Neel syndrome as complication of acute hepatitis. Nord. méd. 43, 599.

Eiseman, B. (1966) Treatment of hepatic coma by extracorporeal liver perfusion. Ann. roy. Coll. Surg. Engl. 38, 329.

Fenton, J.C.B., KNight, E.J. \& Humpherson, P.L. (1966) Milk and cheese diet in portal systemic encephalopathy. Lancet, i, 164.

GiBson, J.B. (1963) Encephalopathy after portocaval shunt. Brit. med. J. i, 1652.

Grace, N.D., Muench, H. \& Chalmers, T.C. (1966) The present status of shunts for portal hypertension in cirrhosis. Gastroenterology, 50, 684.

Jones, E.A., Clain, D., Clink, H.M., MacGillivray, M. \& SHERLOCK, S. (1967) Hepatic coma due to acute hepatic necrosis treated by exchange transfusion. Lancet, ii, 169.

LANCE, J.W. \& ADAMS, R.D. (1963) The syndrome of intention or action myoclonus as a sequel to hypoxic encephalopathy. Brain, 86, 111.

Liversedge, L.A. \& RAwSON, M.D. (1966) Myelopathy in hepatic disease and portosystemic venous anastomosis. Lancet, i, 277.

LuCKE, B. \& Mallory, T. (1946) The fulminant form of epidemic hepatitis. Amer. J. Path. 22, 867.

MACbeth, W.A.A.G., Kass, E.H. \& MCDermotT, W.V. (1965) Treatment of hepatic encephalopathy by alteration of intestinal flora with Lactobacillus acidophilus. Lancet, $\mathbf{i}$, 399. 
McDermott, W.V., Victor, M. \& Point, W.W. (1962) Exclusion of the colon in the treatment of hepatic encephalopathy. New Engl. J. Med. 267, 850.

MorRIS, T.Q., Gocke, D.J. \& SARDI, G.F. (1967) Exchange transfusion treatment of fulminating viral hepatitis in the dog. J. clin. Invest. 46, 1098.

Moser, H.W., Efron, M.L., Brown, H., Diamond, R. \& Neumann, C. G. (1967) Argininosuccinic aciduria. Review of two new cases and demonstration of intermittent elevation of blood ammonia. Amer. J. Med. 42, 9.

Ortiz-VÁzQUez, J. (1967) Neuropathy and liver disease (Lettes). Lancet, ii, 263.

Osborn, S.B. \& WALShe, J.M. (1967) Studies with radioactive copper $\left({ }^{61} \mathrm{Cu}\right.$ and $\left.{ }^{67} \mathrm{Cu}\right)$, in relation to the natural history of Wilson's disease. Lancet, i, 346.

Pearce, J.M.S. (1963) Focal neurological syndromes in hepatic failure. Postgrad. med. J. 39, 653.

READ, A.E. (1965) In: Recent Advances in Gastroenterology (Ed. by J. Badenoch and B. N. Brooke), p. 314. Churchill, London.

Read, A.E., McCarthy, C.F., Heaton, K.W. \& Laidlow, J. (1966) Lactobacillus acidophilus (Enpac) in treatment of hepatic encephalopathy. Brit. med. J. i, 1267.

Read, A.E., Sherlock, S., Laidlow, J. \& Walker, J.G. (1967) The neuro-psychiatric syndromes associated with chronic liver disease and an extensive portal-systemic collateral circulation. Quart. J. Med. 36, 135.

SAUNDERS, S.J. (1967) The treatment of hepatic coma by exchange transfusion. In: Colston Papers: Liver Disease (Ed. by A. E. Read). Blackwell Scientific Publications, Oxford.
Schenker, S., McCandless, D.W., Brophy, E. \& Lewis, M.S. (1967) Studies on the intracerebral toxicity of ammonia. J. clin. Invest. 46, 838.

SummersKILL, W.H.J. (1966) On the origin and transfer of ammonia in the human gastrointestinal tract. Medicine, 45, 491.

Summerskill, W.H.J., Davidson, E.A., Sherlock, S. \& STEINER, R.E. (1956) The neuro-psychiatric syndrome associated with hepatic cirrhosis and an extensive portal collateral circulation. Quart. J. Med. 25, 245.

Thompson, E.N., Williams, R. \& Sherlock, S. (1964) Liver function in extrahepatic portal hypertension. Lancet, ii, 1352.

Toghill, P.J., Johnston, A.W. \& Smith, J.F. (1967) Choreoathetosis in porto-systemic encephalopathy. J. Neurol. Neurosurg. Psychiat. 30, 358.

Victor, M., Adams, R.D. \& Cole, M. (1965) The acquired (non-Wilsonian) type of chronic hepatocerebral degeneration. Medicine, 44, 345.

Victor, M., Adams, R.D. \& Mancall, E.L. (1959) A restricted form of cerebellar cortical degeneration occurring in alcoholic patients. Arch. Neurol. (Chic.), 1, 579.

Walker, J.G., Emlyn-Williams, A., Craigie, A., Rosenoer, V.M., AGNew, J. \& Sherlock, S. (1965) Treatment of chronic portal-systemic encephalopathy by surgical exclusion of the colon. Lancet, ii, 861 .

WatTs, J. McK., Douglas, M.C., Dudley, H.A.F., GurR, F.W. \& OWEN, J.A. (1967) Heterologous liver perfusion in acute hepatic failure. Brit. med. J. i, 341.

Zieve, L. (1966) Pathogenesis of hepatic coma. Arch. iniern. Med. 118, 211. 